\title{
Air Pollution and Epigenetics
}

\author{
Aleena Syed, Kinjal Hew, Arunima Kohli, Greg Knowlton, Kari C. Nadeau \\ Department of Pediatrics, Division of Immunology, Allergy and Rheumatology, Stanford University School of Medicine, Stanford, \\ USA. \\ Email: knadeau@stanford.edu
}

Received May $25^{\text {th }}, 2013$; revised June $29^{\text {th }}, 2013$; accepted July $26^{\text {th }}, 2013$

Copyright (C) 2013 Aleena Syed et al. This is an open access article distributed under the Creative Commons Attribution License, which permits unrestricted use, distribution, and reproduction in any medium, provided the original work is properly cited.

\begin{abstract}
Air pollution is a global problem with far-reaching environmental impacts. Exposure has been linked to a number of different adverse health effects. Understanding the impact of ambient air pollution is complicated given the diversity of both the pollutants involved as well as the complexity of associated diseases. While we see a positive correlation between levels of exposure and health issues, the mechanisms of pathogenesis are still under investigation. The study of epigenetic regulation as it relates to disease is emerging as an exciting new way to interpret the possible effects of ambient air pollution on DNA. In this review we provide an overview of epigenetic modifications as well as an analysis of how epigenetic mechanisms are involved in the adverse effects associated with the most common components of ambient air pollution.
\end{abstract}

Keywords: Air Pollution; Epigenetics; DNA Methylation; Histone Acetylation; microRNA; PAH; DEP; Ozone

\section{Introduction}

Recent epidemiological studies have shown that ambient air pollution exposure is associated with increased mortality and higher incidence of respiratory diseases such as asthma, chronic obstructive pulmonary disease, and cancer [1]. Adverse impacts of air pollutant exposure have a profound effect on morbidity and mortality; according to one study, ambient air pollution caused $6 \%$ of total mortality, or more than 40,000 attributable cases, per year [2].

In general, the worldwide trend is towards a reduction in the concentrations of air pollutants because of increasingly strong restrictions from local governments and international organizations. In developing countries, rising concentrations of air pollutants pose an imminent threat to public health, and even in countries that have made the improvements necessary to meet World Health Organization (WHO) air quality standards, the adverse health effects of air pollutants remain problematic [3,4].

Major air pollutants that have been linked to adverse health outcomes include polycyclic aromatic hydrocarbons (PAH), ozone, particulate matter (PM) and diesel exhaust particles (DEP), and cigarette smoke [5-8]. Although studies have found an associative link between ambient air pollution and the incidence of respiratory diseases, the exact, causative mechanisms of these air pollutants are not yet fully understood. Recently, numerous publications have linked induction of diseases such as asthma via ambient air pollution exposure to epigenetic mechanisms, among others [9-12]. Epigenetics is defined as the study of heritable changes in gene expression that do not affect underlying DNA sequences. The most common epigenetic mechanisms include DNA methylation, histone modifications, and microRNA (miRNA) [13]. This review aims to provide a brief overview of epigenetic modifications (summarized in Figure 1) and explain the mechanisms through which the primary types of ambient air pollution can lead to adverse health effects.

\section{Epigenetic Mechanisms}

\subsection{DNA Methylation}

DNA methylation is necessary for regulating normal gene expression and can be greatly impacted by environmental factors. Methylation changes are reversible and mediated by DNA methyltransferase (DNMT) and demethylase. The addition of methyl groups generally occurs at cytosine residues adjacent to guanine nucleotides ( $\mathrm{CpG}$ sites) within enhancer regions of candidate genes. The addition of methyl groups (methylation) prevents transcription, silencing gene expression. By contrast, the removal of methyl groups (demethylation) allows transcription 


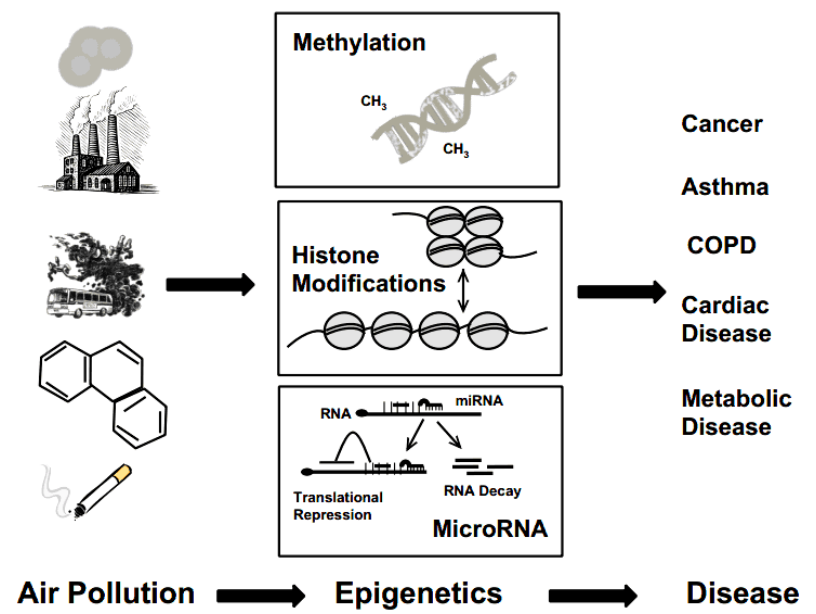

Figure 1. Epigenetic mechanisms involved in air pollutant induced adverse health effects.

factor binding, activating and enhancing gene expression. Methylation changes are dynamic and have been implicated in the natural course of mammalian development [14]. Environmental factors like ambient air pollution can affect global methylation patterns. Some of these epigenetic changes have been linked to disease.

\subsection{Histone Acetylation}

Histones are highly alkaline proteins that arrange DNA into structures known as nucleosomes. These nucleosomes function like spools around which the DNA coils, playing an important role in the regulation of gene accessibility [15]. Modifications to the histones therefore alter this regulation. Several potential modification mechanisms exist, including: 1) Acetylation, whereby acetyltransferases add an acetyl group to lysine residues in the histone tail, neutralizing their positive charge and therefore decreasing histones' affinity for DNA and increasing transcription; 2) Methylation, which-similarly to DNA methylation-involves the transfer of a methyl group by methyltransferases to or from lysine or arginine to create an unmodified, mono-, di-, or tri-methylated state, with certain modifications (H3K4me and H3K36me) associated with activation of transcription and others associated with repression of transcription (H3K9 and H3K27); 3) Phosphorylation, the addition of a phosphate group, which increases the negative charge of the histone and therefore increases repulsion between the histone and the DNA strand, increasing accessibility of the DNA; and 4) Ubiquitylation, in which a ubiquitin protein (76 amino acids) is added to a lysine side chain, with varying effects on transcription that seem to be context-dependent [15] [16]. There appears to be cross-talk not only between these mechanisms of histone modification, but also between histone modification and other epigenetic mechanisms, i.e., DNA methylation and micro RNA $[15,16]$.

\section{3. microRNAs}

MicroRNAs (miRNAs) are an abundant class of singlestranded small non-coding RNAs, approximately 19 - 22 nucleotides long, which regulate gene expression posttransciptionally. miRNAs typically function by negatively regulating mRNA processing, stability, and translation and thereby represent a novel layer in regulation of flow of genetic information and cellular functions. miRNAs are encoded in genomic DNA and are transcribed by RNA polymerase II into long primary transcripts called pri-miRNA. This pri-miRNA is sequentially processed in the cell nucleus and then in the cytoplasm to generate mature active miRNA [17]. Recent evidence suggests that miRNA expression maybe implicated in several developmental, inflammatory, apoptotic, and cellular signal transduction pathways affecting multiple disease pathogenesis, including cardiovascular disease, cancer, metabolic diseases, lung development, and respiratory disease, etc. [18-25].

\section{Common Air Pollutants}

\subsection{Polycyclic Aromatic Hydrocarbons (PAH)}

Polycyclic aromatic hydrocarbons (PAHs) represent a complex class of environmental pollutants derived from the incomplete combustion of organic compounds. These relatively stable compounds are comprised of multiple, fused, benzene rings. The major sources of PAH include burning of biomass, wildfires, and vehicular emissions $[26,27]$. The primary sources of PAH production vary from country to country, with developing nations responsible for greater emissions than developed nations due in large part to disparities in production technology [27]. Exposure to PAH is most significant in urban regions marked by high levels of both industrial development as well as traffic [26,27]; significant global contributors include China, India, and Brazil [27].

Several studies have assessed occupational health risks in individuals exposed to disproportionate levels of PAHs, such as traffic controllers and industrial workers [28-31]. These studies show that PAH can be a potent carcinogen and has also been linked to adverse respiratory effects $[26,27,32,33]$. Additionally, PAH exposure has been associated with the activation of DNA damage signaling, with multiple PAHs exerting more extensive damage than one polycyclic compound alone [34].

PAH exposure can begin in the womb and, through epigenetic modifications, can have long-lasting effects. Increased maternal exposure to PAH has been associated with increased DNA methylation of the asthma related gene acyl-CoA synthestase long-chain family member 3 (ACSL3) and subsequent increases in the prevalence of childhood asthma [8]. In another study, in vitro exposure was associated with hypermethylation of the asthma- 
related gene interferon-gamma $(I F N-\gamma)$ and consequent decreases in its expression. $I F N-\gamma$ is thought to play a protective role in asthma and allergic disease; thus, decreases in expression may be pathogenic [35]. Exposure to ambient air pollution (which includes PAHs) has been linked to increased methylation in the forkhead box protein 3 (FOXP3) locus of regulatory $\mathrm{T}$ cells (Treg), and subsequent functional deficits that could contribute to asthma pathogenesis [36]. High levels of PAH exposure in coke oven workers has been correlated with hypomethylation of the O6-methyl-guanine-DNA methyltransferase (MGMT), contributing to genomic instability in lymphocytes [28], which may in turn increase the risk of carcinogenesis.

PAH appears to alter methylation patterns, which could account for the far-reaching impact of both preand postnatal chronic exposure to PAH. However, it is still not clear how PAH actually alters methylation. One hypothesis is that these epigenetic changes are mediated via the aryl hydrocarbon receptor (AhR). AhRs are expressed on several cell types and act as an environmental sensor for toxicity. Activation of AhR signals a number of pathways involved in inflammation and the immune response [37]. The effects of AhR activation appear to be ligand-dependent; thus, different PAHs may have varied effects. Binding of the PAH phenanthrene to AhR on the surface of Treg cells results in increased methylation of the FOXP3 locus. This methylation diminishes the suppressive function of Treg and appears to convert them to T helper type 2 cells (Th2) [38], producing an inflammatory response. Overactivation of Th2 cells and deficits in natural regulatory mechanisms have both been linked to allergic disorders [39]. This imbalance may be induced through PAH-mediated activation of AhR.

\subsection{Ozone}

Ground-level ozone is one of six criteria pollutants for which National Ambient Air Quality Standards (NAAQS) are set by the United States Environmental Protection Agency, with the current standard set at $0.075 \mathrm{ppm} / 8 \mathrm{~h}$. Epidemiological studies have demonstrated a clear pathologic association between ambient ozone levels and respiratory health, including respiratory allergies, lung function deficits, increased prevalence of asthma, and hospital admissions [40-42]. A recent study showed that ozone inhalation contributed to both human morbidity and mortality and each 10 parts per billion (ppb) increase in ozone was associated with approximately a $0.52 \%$ increase in mortality [43].

Despite the non-antigenic nature of ozone, recent evidence suggests that ozone may indirectly modulate adaptive immunity by promoting the activation of antigen presenting cells [44-46]. Toll-like Receptor (TLR) 4 has been identified as an essential susceptibility gene for the inflammatory and physiologic effects of ozone exposure in certain mouse strains, and is an important clue to the link between ozone and microbial immunity $[47,48]$. Recent evidence in intestinal epithelial cells suggests that TLR4 gene expression downregualted via epigenetic modifications including histone deacetylation and DNA methylation to prevent excessive inflammatory responses [49]. Although, a similar mechanism of regulation of TLR responses post ozone exposure might be at play in the lung epithelial cells no studies thus far have demonstrated this. More recently multiple miRNAs have been implicated in the regulation of TLR4 signaling pathway [50-56]. TLR signaling pathways consist of both MyD88 dependent and independent pathways [57]. MyD88 dependent pathway signals through IRAK1 and TRAF6 leading to nuclear translocation of NFkB and activation of AP-1. Both IRAK1 and TRAF6 are targets of miR146 [51]. The MyD88 independent pathway signals through TRIF, inducing IRF transcription factors resulting in type 1 interferon production. TRIF and another adaptor TAB2 in this pathway have known to be regulated by miR-155 $[50,58]$.

\subsection{Particulate Matter (PM) and Deisel Exhaust Particles (DEP)}

Ambient PM has been associated with adverse health outcomes but the mechanisms linking PM inhalation to adverse health are not completely understood. A mouse model study using intranasal sensitization to Aspergillus fumigates and inhaled DEP exposure showed changes in DNA methylation involved in two important genes involved in asthma, $I L-4$ and $I F N-\gamma$, which positively correlated with increased total IgE secretion, which is involved in asthma pathogenesis [59]. In humans, a recent profiling study of 141 subjects showed that exposure to airborne PM, particularly black carbon and sulfate were significantly associated with changes in DNA methylation pattern of genes involved in asthma [60]. In a study of steel plant workers exposed to $\mathrm{PM}<10 \mu \mathrm{m}$, researchers showed significant alterations in blood DNA methylation both globally in the Alu and LINE-1 repetitive elements, involved in immune inflammatory response, as well as gene-specific methylation of iNOS promoter [10]. Oxidative and nitrosative stress have been implicated in mediating airway inflammation involved in asthma development and fractional concentration of exhaled nitric oxide (FeNO) has been used a biomarker to predict airway inflammation and asthma development.

Multiple studies show evidence of PM with ozone exposure linked to higher levels of FeNO, particularly in children [61-63]. The first study to show evidence linking PM exposure induced epigenetic modification with phenotype expression showed a significant association between exposure to short term (7 days) of $\mathrm{PM}<2.5 \mu \mathrm{m}$ 
with lower NOS2 methylation and correlation with FeNO levels [64]. A global methylation profiling study, using mice to mimic long term exposure of humans to ambient particulate air pollution near steel mills and major highways, showed hypermethylation in sperm DNA, which persisted even after exposure ceased. These mice also showed more DNA damage and higher frequencies in DNA mutations compared to mice exposed to filtered air, indicating potential increase in mutagenicity [65]. In vitro studies of bronchial epithelial cells using the BEAS-2B cell line showed that exposure to DEP resulted in histone modification including selective degradation of histone deacetylase (HDAC) 1 and activation of histone acetyltransferases (HAT) p300 as well as increased acetylation of histone $\mathrm{H} 4$ in the promoter region of cyclooxygenase-2 (COX-2), an inflammatory mediator. Expression of COX-2 was increased with DEP exposure indicating that DEP exposure resulted in histone modifications resulting in increased inflammation [66]. In another profiling study evaluating PM exposure effects on miRNA expression using a microarray approach, researchers found four PM-sensitive miRNAs that were expressed differentially post exposure compared to baseline (miR-421, miR-146a, miR-29a, and miR-let7g). Upon further analyzing miRNA expression and candidate inflammatory genes, the authors concluded that exposure to PM for 3 days resulted in inflammatory gene regulation through PM responsive miRNAs [67].

\subsection{Cigarette Smoke}

Cigarette smoke, both primary and secondary, is one of the more widely studied environmental exposures, particularly with regard to gene-environment interactions. Exposure to cigarette smoke has been associated with the development and exacerbation of several diseases, most prominently respiratory diseases such as COPD, asthma, and lung cancer, as well as cardiovascular disease and other cancers [68]. The mechanisms of these relationships are not fully understood, but it seems that epigenetics may play a major role in mediating the effects of cigarette smoke on human health.

A landmark study published in 2005 found that increased maternal and grandmaternal smoking was associated with increased asthma in children [69], suggesting a generational effect consistent with epigenetic modification. Indeed, several studies have associated in utero exposure to cigarette smoke via maternal smoking with global changes to DNA methylation [70-72] as well as with alterations in the methylation of specific genes implicated in growth [73], processing of toxicants and carcinogens [74,75], and cancer and immune functions [76]. Maternal smoking during pregnancy has also been associated with downregulation of miRNA implicated in growth and development [77].
Cigarette smoke exposure, both primary and secondary, has also been associated with alterations in DNA methylation, with global changes observed [78] as well as changes in genes relevant to asthma $[13,79]$, cardiovascular disease [80], lung cancer [81-83], COPD [80], bladder cancer $[84,85]$, and colorectal cancer [86] among others, with some suggestions of differences between current and former smokers [87].

Similar alterations due to smoke exposure have also been observed in histone modifications, including reduction of histone deacetylases (specifically histone deacetylases 2 and 3) that have implications in COPD and asthma [88-91], and phosphorylation associated with generation of double-stranded DNA breaks [92,93], as well as methylation [82], and acetylation and phosphoacetylation $[94,95]$. Many histone modifications have been studied in the context of changes in behavior of the protein complex NF- $\kappa \mathrm{B}$, which is important for control of DNA transcription and has been found to be upregulated when histone deacetylases are reduced [96].

Smoke exposure has also been found to be associated with changes in micro RNA expression. Differences in plasma miRNA expression have been found between smokers and nonsmokers [97], as well as decreases in global miRNA expression in smokers versus nonsmokers $[98,99]$. Exposure to cigarette smoke condensate in culture has been associated with increased oncomir miRNA [100], and decreased tumor suppressor miRNA [101]; nicotine exposure has also been found to alter miRNA expression in adult human stem cells, with detrimental effects on regenerative potential [102]. Overall, these changes seem to suggest a potential mechanistic link to cancer more than any other disease associated with cigarette smoking.

It is important to note that cigarette smoke contains hundreds of compounds, including such common environmental pollutants as PM2.5, PM10, PAHs, cadmium, lead, and arsenic. This suggests that it is important to consider potential modulating effects of cigarette smoke exposure on the impacts of these other pollutants. Various studies have found that cigarette smoke exposure modulates both clinical symptoms and methylation patterns associated with air pollution exposures, exacerbating disease phenotypes [103,104].

\section{Conclusion}

Recent efforts have been made to curb the global production of air pollutants, but we are only beginning to uncover their impact. Here we outline the adverse health effects associated with ambient air pollution and suggest the involvement of epigenetic modifications, including DNA methylation, histone acetylation, and microRNAs. Many of these epigenetic changes are thought to be heritable; thus, adverse events associated with ambient air 
pollution can have long-lasting, transgenerational impacts. Genetics have already been implicated in the pathogenesis of many disorders, like asthma and cancer that are also subsequently linked to ambient air pollution exposure. The study of genetics and epigenetics is vital to the understanding of ambient air pollution and could be useful in identifying biomarkers for those individuals most likely to develop health problems in response to exposure.

\section{REFERENCES}

[1] A. J. Cohen, et al., "The Global Burden of Disease Due to Outdoor Air Pollution," Journal of Toxicology and Environmental Health, Part A: Current Issues, Vol. 68, No. 13-14, 2005, pp. 1301-1307. doi:10.1080/15287390590936166

[2] N. Kunzli, et al., "Public-Health Impact of Outdoor and Traffic-Related Air Pollution: A European Assessment," Lancet, Vol. 356, No. 9232, 2000, pp. 795-801. doi:10.1016/S0140-6736(00)02653-2

[3] J. M. Baldasano, E. Valera and P. Jimenez, "Air Quality Data from Large Cities," Science of the Total Environment, Vol. 307, No. 1-3, 2003, pp. 141-165. doi:10.1016/S0048-9697(02)00537-5

[4] J. W. Holloway, et al., "Genomics and the Respiratory Effects of Air Pollution Exposure," Respirology, Vol. 17, No. 4, 2012, pp. 590-600. doi:10.1111/j.1440-1843.2012.02164.x

[5] C. Carlsten and E. Melen, "Air Pollution, Genetics, and Allergy: An Update," Current Opinion in Allergy \& Clinical Immunology, Vol. 12, No. 5, 2012, pp. 455-460. doi:10.1097/ACI.0b013e328357cc55

[6] K. Ito, et al., "Cigarette Smoking Reduces Histone Deacetylase 2 Expression, Enhances Cytokine Expression, and Inhibits Glucocorticoid Actions in Alveolar Macrophages," FASEB Journal, Vol. 15, No. 6, 2001, pp. 1110-1112.

[7] L. Corson, et al., "Prenatal Allergen and Diesel Exhaust Exposure and Their Effects on Allergy in Adult Offspring Mice," Allergy, Asthma \& Clinical Immunology, Vol. 6, No. 1, 2010, p. 7. doi:10.1186/1710-1492-6-7

[8] F. Perera, et al., "Relation of DNA Methylation of 5'-CpG Island of ACSL3 to Transplacental Exposure to Airborne Polycyclic Aromatic Hydrocarbons and Childhood Asthma," PLoS One, Vol. 4, No. 2, 2009, p. e4488. doi:10.1371/journal.pone.0004488

[9] K. Nadeau, C. McDonald-Hyman, B. Pratt, B. Noth, K. Hammond, J. Balmes and I. Tager, "Ambient Air Pollution Impairs Regulatory T-Cell Function in Asthma," Journal of Allergy and Clinical Immunology, Vol. 126, No. 4, 2010, pp. 845-852.

[10] L. Tarantini, et al., "Effects of Particulate Matter on Genomic DNA Methylation Content and iNOS Promoter Methylation," Environmental Health Perspectives, Vol. 117, No. 2, 2009, pp. 217-222.

[11] C. V. Breton, et al., "DNA Methylation in the Arginase-
Nitric Oxide Synthase Pathway Is Associated with Exhaled Nitric Oxide in Children with Asthma," American Journal of Respiratory and Critical Care Medicine, Vol. 184, No. 2, 2011, pp. 191-197. doi:10.1164/rccm.201012-2029OC

[12] A. Baccarelli, et al., "Rapid DNA Methylation Changes after Exposure to Traffic Particles," American Journal of Respiratory and Critical Care Medicine, Vol. 179, No. 7, 2009, pp. 572-578. doi:10.1164/rccm.200807-1097OC

[13] S. Lovinsky-Desir and R. L. Miller, "Epigenetics, Asthma, and Allergic Diseases: A Review of the Latest Advancements," Current Allergy and Asthma Reports, Vol. 12, No. 3, 2012, pp. 211-220. doi:10.1007/s11882-012-0257-4

[14] Z. D. Smith and A. Meissner, "DNA Methylation: Roles in Mammalian Development," Nature Reviews: Genetics, Vol. 14, No. 3, 2013, pp. 204-220. doi:10.1038/nrg3354

[15] G. E. Zentner and S. Henikoff, "Regulation of Nucleosome Dynamics by Histone Modifications," Nature Structural \& Molecular Biology, Vol. 20, No. 3, 2013, pp. 259-266. doi: $10.1038 / \mathrm{nsmb} .2470$

[16] I. V. Yang and D. A. Schwartz, "Epigenetic Mechanisms and the Development of Asthma," The Journal of Allergy and Clinical Immunology, Vol. 130, No. 6, 2012, pp. 1243-1255. doi:10.1016/j.jaci.2012.07.052

[17] D. P. Bartel, "MicroRNAs: Genomics, Biogenesis, Mechanism, and Function," Cell, Vol. 116, No. 2, 2004, pp. 281-297. doi:10.1016/S0092-8674(04)00045-5

[18] C. Z. Chen, et al., "MicroRNAs Modulate Hematopoietic Lineage Differentiation," Science, Vol. 303, No. 5654, 2004, pp. 83-86. doi:10.1126/science. 1091903

[19] W. P. Kloosterman, et al., "Targeted Inhibition of miRNA Maturation with Morpholinos Reveals a Role for miR-375 in Pancreatic Islet Development," PLoS Biology, Vol. 5, No. 8, 2007, p. e203. doi:10.1371/journal.pbio.0050203

[20] C. Fernandez-Hernando, et al., "MicroRNAs in Metabolic Disease," Arteriosclerosis, Thrombosis, and Vascular Biology, Vol. 33, No. 2, 2013, pp. 178-185. doi:10.1161/ATVBAHA.112.300144

[21] D. Quiat and E. N. Olson, "MicroRNAs in Cardiovascular Disease: From Pathogenesis to Prevention and Treatment," The Journal of Clinical Investigation, Vol. 123, No. 1, 2013, pp. 11-18. doi:10.1172/JCI62876

[22] C. Baer, R. Claus and C. Plass, "Genome-Wide Epigenetic Regulation of miRNAs in Cancer," Cancer Research, Vol. 73, No. 2, 2013, pp. 473-477. doi:10.1158/0008-5472.CAN-12-3731

[23] S. P. Nana-Sinkam, et al., "Integrating the MicroRNome into the Study of Lung Disease," American Journal of Respiratory and Critical Care Medicine, Vol. 179, No. 1, 2009, pp. 4-10. doi:10.1164/rccm.200807-1042PP

[24] R. Schickel, et al., "MicroRNAs: Key Players in the Immune System, Differentiation, Tumorigenesis and Cell Death," Oncogene, Vol. 27, No. 45, 2008, pp. 5959-5974. doi:10.1038/onc.2008.274

[25] N. Yanaihara, et al., "Unique microRNA Molecular Profiles in Lung Cancer Diagnosis and Prognosis," Cancer Cell, Vol. 9, No. 3, 2006, pp. 189-198. doi:10.1016/j.ccr.2006.01.025 
[26] S. Vardoulakis, et al., "Impact and Uncertainty of a Traffic Management Intervention: Population Exposure to Polycyclic Aromatic Hydrocarbons," Science of the Total Environment, Vol. 394, No. 2-3, 2008, pp. 244-251. doi:10.1016/j.scitotenv.2008.01.037

[27] H. Shen, et al., "Global Atmospheric Emissions of Polycyclic Aromatic Hydrocarbons from 1960 to 2008 and Future Predictions," Environmental Science \& Technology, Vol. 47, No. 12, 2013, pp. 6415-6424. doi:10.1021/es $400857 \mathrm{z}$

[28] H. Duan, et al., "Global and MGMT Promoter Hypomethylation Independently Associated with Genomic Instability of Lymphocytes in Subjects Exposed to HighDose Polycyclic Aromatic Hydrocarbon," Archives of Toxicology, 2013. (in Press) doi:10.1007/s00204-013-1046-0

[29] H. B. Huang, et al., "Exposure to Heavy Metals and Polycyclic Aromatic Hydrocarbons and DNA Damage in Taiwanese Traffic Conductors," Cancer Epidemiology, Biomarkers \& Prevention, Vol. 22, No. 1, 2013, pp. 102108. doi:10.1158/1055-9965.EPI-12-0706

[30] S. Pavanello, et al., "Shorter Telomere Length in Peripheral Blood Lymphocytes of Workers Exposed to Polycyclic Aromatic Hydrocarbons," Carcinogenesis, Vol. 31, No. 2, 2010, pp. 216-221. doi:10.1093/carcin/bgp278

[31] B. Ouyang, et al., "Hypomethylation of Dual Specificity Phosphatase 22 Promoter Correlates with Duration of Service in Firefighters and Is Inducible by Low-Dose Benzo[a]Pyrene," Journal of Occupational \& Environmental Medicine, Vol. 54, No. 7, 2012, pp. 774-780. doi:10.1097/JOM.0b013e31825296bc

[32] N. M. Al-Daghri, et al., "Polycyclic Aromatic Hydrocarbon Exposure and Pediatric Asthma in Children: A CaseControl Study," Environmental Health, Vol. 12, 2013, p. 1. doi:10.1186/1476-069X-12-1

[33] S. M. Ho, et al., "Environmental Epigenetics and Its Implication on Disease Risk and Health Outcomes," ILAR Journal, Vol. 53, No. 3-4, 2012, pp. 289-305. doi:10.1093/ilar.53.3-4.289

[34] I. W. Jarvis, et al., "Persistent Activation of DNA Damage Signaling in Response to Complex Mixtures of PAHs in Air Particulate Matter," Toxicology and Applied Pharmacology, Vol. 266, No. 3, 2013, pp. 408-418. doi:10.1016/j.taap.2012.11.026

[35] W. Y. Tang, et al., "Maternal Exposure to Polycyclic Aromatic Hydrocarbons and 5'-CpG Methylation of Interferon-Gamma in Cord White Blood Cells," Environmental Health Perspectives, Vol. 120, No. 8, 2012, pp. 1195-1200. doi:10.1289/ehp.1103744

[36] K. Nadeau, et al., "Ambient Air Pollution Impairs Regulatory T-Cell Function in Asthma," Journal of Allergy and Clinical Immunology, Vol. 126, No. 4, 2010, pp. 845852.

[37] E. A. Stevens, J. D. Mezrich and C. A. Bradfield, "The Aryl Hydrocarbon Receptor: A Perspective on Potential Roles in the Immune System," Immunology, Vol. 127, No. 3, 2009, pp. 299-311. doi:10.1111/j.1365-2567.2009.03054.x

[38] J. Liu, et al., "Epigenetically Mediated Pathogenic Effects of Phenanthrene on Regulatory T Cells," Journal of Toxicology, Vol. 2013, 2013, Article ID: 967029.

[39] M. Akdis, et al., "Immune Responses in Healthy and Allergic Individuals Are Characterized by a Fine Balance between Allergen-Specific T Regulatory 1 and T Helper 2 Cells," The Journal of Experimental Medicine, Vol. 199, No. 11, 2004, pp. 1567-1575. doi:10.1084/jem.20032058

[40] B. Fauroux, et al., "Ozone: A Trigger for Hospital Pediatric Asthma Emergency Room Visits," Pediatric Pulmonology, Vol. 30, No. 1, 2000, pp. 41-46. doi:10.1002/1099-0496(200007)30:1<41::AID-PPUL7>3. $0 . \mathrm{CO} ; 2-4$

[41] K. Moore, et al., "Ambient Ozone Concentrations Cause Increased Hospitalizations for Asthma in Children: An 18-Year Study in Southern California," Environmental Health Perspectives, Vol. 116, No. 8, 2008, pp. 10631070. doi:10.1289/ehp.10497

[42] T. Frischer, et al., "Lung Function Growth and Ambient Ozone: A Three-Year Population Study in School Children," American Journal of Respiratory and Critical Care Medicine, Vol. 160, No. 2, 1999, pp. 390-396. doi:10.1164/ajrccm.160.2.9809075

[43] M. L. Bell and F. Dominici, "Effect Modification by Community Characteristics on the Short-Term Effects of Ozone Exposure and Mortality in 98 US Communities," American Journal of Epidemiology, Vol. 167, No. 8, 2008, pp. 986-997. doi:10.1093/aje/kwm396

[44] J. W. Hollingsworth, et al., "Ozone Activates Pulmonary Dendritic Cells and Promotes Allergic Sensitization through a Toll-Like Receptor 4-Dependent Mechanism," Journal of Allergy and Clinical Immunology, Vol. 125, No. 5, 2010, pp. 1167-1170. doi:10.1016/j.jaci.2010.03.001

[45] E. Koike and T. Kobayashi, "Ozone Exposure Enhances Antigen-Presenting Activity of Interstitial Lung Cells in Rats," Toxicology, Vol. 196, No. 3, 2004, pp. 217-227. doi:10.1016/j.tox.2003.10.007

[46] J. C. Lay, et al., "Ozone Enhances Markers of Innate Immunity and Antigen Presentation on Airway Monocytes in Healthy Individuals," Journal of Allergy and Clinical Immunology, Vol. 120, No. 3, 2007, pp. 719-722. doi:10.1016/j.jaci.2007.05.005

[47] J. W. Hollingsworth 2nd, et al., "The Role of Toll-Like Receptor 4 in Environmental Airway Injury in Mice," American Journal of Respiratory and Critical Care Medicine, Vol. 170, No. 2, 2004, pp. 126-132. doi:10.1164/rcem.200311-1499OC

[48] S. R. Kleeberger, et al., "Linkage Analysis of Susceptibility to Ozone-Induced Lung Inflammation in Inbred Mice," Nature Genetics, Vol. 17, No. 4, 1997, pp. 475478. doi:10.1038/ng1297-475

[49] K. Takahashi, et al., "Epigenetic Regulation of TLR4 Gene Expression in Intestinal Epithelial Cells for the Maintenance of Intestinal Homeostasis," The Journal of Immunology, Vol. 183, No. 10, 2009, pp. 6522-6529. doi:10.4049/jimmunol.0901271

[50] M. Ceppi, et al., "MicroRNA-155 Modulates the Interleukin-1 Signaling Pathway in Activated Human MonocyteDerived Dendritic Cells," Proceedings of the National 
Academy of Sciences of the United States of America, Vol. 106, No. 8, 2009, pp. 2735-2740.

doi:10.1073/pnas.0811073106

[51] K. D. Taganov, et al., "NF-KappaB-Dependent Induction of MicroRNA miR-146, an Inhibitor Targeted to Signaling Proteins of Innate Immune Responses," Proceedings of the National Academy of Sciences of the United States of America, Vol. 103, No. 33, 2006, pp. 12481-12486. doi: $10.1073 /$ pnas.0605298103

[52] M. Rossato, et al., "IL-10-Induced MicroRNA-187 Negatively Regulates TNF-Alpha, IL-6, and IL-12p40 Production in TLR4-Stimulated Monocytes," Proceedings of the National Academy of Sciences of the United States of America, Vol. 109, No. 45, 2012, pp. E3101-E3110. doi:10.1073/pnas.1209100109

[53] L. Lai, et al., "MicroRNA-92a Negatively Regulates TollLike Receptor (TLR)-Triggered Inflammatory Response in Macrophages by Targeting MKK4 Kinase," The Journal of Biological Chemistry, Vol. 288, No. 11, 2013, pp. 7956-7967. doi:10.1074/jbc.M112.445429

[54] M. A. Nahid, et al., "Regulation of TLR2-Mediated Tolerance and Cross-Tolerance through IRAK4 Modulation by miR-132 and miR-212," The Journal of Immunology, Vol. 190, No. 3, 2013, pp. 1250-1263. doi:10.4049/jimmunol.1103060

[55] D. Li, et al., "TLR4 Signaling Induces the Release of Microparticles by Tumor Cells that Regulate Inflammatory Cytokine IL-6 of Macrophages via MicroRNA Let-7b," Oncoimmunology, Vol. 1, No. 5, 2012, pp. 687-693. doi:10.4161/onci.19854

[56] L. A. O’Neill, F. J. Sheedy and C. E. McCoy, "MicroRNAs: The Fine-Tuners of Toll-Like Receptor Signalling," Nature Reviews Immunology, Vol. 11, No. 3, 2011, pp. 163-175. doi:10.1038/nri2957

[57] S. Akira and K. Takeda, "Toll-Like Receptor Signalling," Nature Reviews Immunology, Vol. 4, No. 7, 2004, pp. 499-511. doi:10.1038/nri1391

[58] E. Tili, et al., "Modulation of miR-155 and miR-125b Levels Following Lipopolysaccharide/TNF-Alpha Stimulation and Their Possible Roles in Regulating the Response to Endotoxin Shock," The Journal of Immunology, Vol. 179, No. 8, 2007, pp. 5082-5089.

[59] J. Liu, et al., "Combined Inhaled Diesel Exhaust Particles and Allergen Exposure Alter Methylation of T Helper Genes and IgE Production in Vivo," Toxicological Sciences, Vol. 102, No. 1, 2008, pp. 76-81. doi:10.1093/toxsci/kfm290

[60] T. Sofer, et al., "Exposure to Airborne Particulate Matter Is Associated with Methylation Pattern in the Asthma Pathway," Epigenomics, Vol. 5, No. 2, 2013, pp. 147-154. doi:10.2217/epi.13.16

[61] J. Saito, et al., "Exhaled Nitric Oxide as a Marker of Airway Inflammation for an Epidemiologic Study in Schoolchildren," Journal of Allergy and Clinical Immunology, Vol. 114, No. 3, 2004, pp. 512-516. doi:10.1016/j.jaci.2004.05.033

[62] R. J. Delfino, et al., "Personal and Ambient Air Pollution is Associated with Increased Exhaled Nitric Oxide in
Children with Asthma," Environmental Health Perspectives, Vol. 114, No. 11, 2006, pp. 1736-1743.

[63] A. Barraza-Villarreal, et al., "Air Pollution, Airway Inflammation, and Lung Function in a Cohort Study of Mexico City Schoolchildren," Environmental Health Perspectives, Vol. 116, No. 6, 2008, pp. 832-838. doi:10.1289/ehp.10926

[64] M. T. Salam, et al., "Genetic and Epigenetic Variations in Inducible Nitric Oxide Synthase Promoter, Particulate Pollution, and Exhaled Nitric Oxide Levels in Children," Journal of Allergy and Clinical Immunology, Vol. 129, No. 1, 2012, pp. 232-239.

[65] C. Yauk, et al., "Germ-Line Mutations, DNA Damage, and Global Hypermethylation in Mice Exposed to Particulate Air Pollution in an Urban/Industrial Location," Proceedings of the National Academy of Sciences of the United States of America, Vol. 105, No. 2, 2008, pp. 605610. doi:10.1073/pnas.0705896105

[66] D. Cao, P. A. Bromberg and J. M. Samet, "COX-2 Expression Induced by Diesel Particles Involves Chromatin Modification and Degradation of HDAC1," American Journal of Respiratory Cell and Molecular Biology, Vol. 37, No. 2, 2007, pp. 232-239. doi:10.1165/rcmb.2006-04490C

[67] V. Motta, et al., "Integrative Analysis of miRNA and Inflammatory Gene Expression after Acute Particulate Matter Exposure," Toxicological Sciences, Vol. 132, No. 2, 2013, pp. 307-316. doi:10.1093/toxsci/kft013

[68] Centers for Disease Control and Prevention, "The Health Consequences of Involuntary Exposure to Tobacco Smoke: A Report of the Surgeon General," Office on Smoking and Health, Atlanta, 2006.

[69] Y. F. Li, et al., "Maternal and Grandmaternal Smoking Patterns Are Associated with Early Childhood Asthma," Chest, Vol. 127, No. 4, 2005, pp. 1232-1241. doi: $10.1378 /$ chest.127.4.1232

[70] C. V. Breton, et al., "Prenatal Tobacco Smoke Exposure Affects Global and Gene-Specific DNA Methylation," American Journal of Respiratory and Critical Care Medicine, Vol. 180, No. 5, 2009, pp. 462-467. doi:10.1164/rccm.200901-0135OC

[71] R. Guerrero-Preston, et al., "Global DNA Hypomethylation Is Associated with in Utero Exposure to Cotinine and Perfluorinated Alkyl Compounds," Epigenetics, Vol. 5, No. 6, 2010, pp. 539-546. doi:10.4161/epi.5.6.12378

[72] C. S. Wilhelm-Benartzi, et al., "In Utero Exposures, Infant Growth, and DNA Methylation of Repetitive Elements and Developmentally Related Genes in Human Placenta," Environmental Health Perspectives, Vol. 120, No. 2, 2012, pp. 296-302. doi:10.1289/ehp.1103927

[73] S. K. Murphy, et al., "Gender-Specific Methylation Differences in Relation to Prenatal Exposure to Cigarette Smoke," Gene, Vol. 494, No. 1, 2012, pp. 36-43. doi:10.1016/j.gene.2011.11.062

[74] M. Suter, et al., "In Utero Tobacco Exposure Epigenetically Modifies Placental CYP1A1 Expression," Metabolism, Vol. 59, No. 10, 2010, pp. 1481-1490. doi:10.1016/j.metabol.2010.01.013 
[75] B. R. Joubert, et al., "450K Epigenome-Wide Scan Identifies Differential DNA Methylation in Newborns Related to Maternal Smoking during Pregnancy," Environmental Health Perspectives, Vol. 120, No. 10, 2012, pp. 14251431.

[76] C. V. Breton, M. T. Salam and F. D. Gilliland, "Heritability and Role for the Environment in DNA Methylation in AXL Receptor Tyrosine Kinase," Epigenetics, Vol. 6, No. 7, 2011, pp. 895-898. doi:10.4161/epi.6.7.15768

[77] M. A. Maccani, et al., "Maternal Cigarette Smoking during Pregnancy Is Associated with Downregulation of miR-16, miR-21, and miR-146a in the Placenta," Epigenetics, Vol. 5, No. 7, 2010, pp. 583-589. doi:10.4161/epi.5.7.12762

[78] S. Wangsri, et al., "Patterns and Possible Roles of LINE-1 Methylation Changes in Smoke-Exposed Epithelia," PLoS ONE, Vol. 7, No. 9, 2012, Article ID: e45292. doi:10.1371/journal.pone.0045292

[79] A. L. Durham, C. Wiegman and I. M. Adcock, "Epigenetics of Asthma," Biochimica et Biophysica Acta, Vol. 1810, No. 11, 2011, pp. 1103-1109. doi:10.1016/i.bbagen.2011.03.006

[80] M. Talikka, et al., "Genomic Impact of Cigarette Smoke, with Application to Three Smoking-Related Diseases," Critical Reviews in Toxicology, Vol. 42, No. 10, 2012, pp. 877-889. doi: $10.3109 / 10408444.2012 .725244$

[81] T. Vaissiere, et al., "Quantitative Analysis of DNA Methylation Profiles in Lung Cancer Identifies Aberrant DNA Methylation of Specific Genes and Its Association with Gender and Cancer Risk Factors," Cancer Research, Vol. 69, No. 1, 2009, pp. 243-252. doi:10.1158/0008-5472.CAN-08-2489

[82] F. Liu, et al., "Epigenomic Alterations and Gene Expression Profiles in Respiratory Epithelia Exposed to Cigarette Smoke Condensate," Oncogene, Vol. 29, No. 25, 2010, pp. 3650-3664. doi:10.1038/onc.2010.129

[83] B. Word, et al., "Cigarette Smoke Condensate Induces Differential Expression and Promoter Methylation Profiles of Critical Genes Involved in Lung Cancer in NL-20 Lung Cells in Vitro: Short-Term and Chronic Exposure," International Journal of Toxicology, Vol. 32, No. 1, 2013, pp. 23-31. doi:10.1177/1091581812465902

[84] D. Volanis, et al., "Molecular Mechanisms in Urinary Bladder Carcinogenesis," Journal of Balkan Union of Oncology, Vol. 16, No. 4, 2011, pp. 589-601.

[85] M. Brait, et al., "Genome-Wide Methylation Profiling and the PI3K-AKT Pathway Analysis Associated with Smoking in Urothelial Cell Carcinoma," Cell Cycle, Vol. 12, No. 7, 2013, pp. 1058-1070. doi:10.4161/cc.24050

[86] D. Limsui, et al., "Cigarette Smoking and Colorectal Cancer Risk by Molecularly Defined Subtypes," Journal of the National Cancer Institute, Vol. 102, No. 14, 2010, pp. 1012-1022. doi:10.1093/jnci/djq201

[87] E. S. Wan, et al., "Cigarette Smoking Behaviors and Time Since Quitting Are Associated with Differential DNA Methylation across the Human Genome," Human Molecular Genetics, Vol. 21, No. 13, 2012, pp. 3073-3082. doi:10.1093/hmg/dds135
[88] H. Yao and I. Rahman, "Role of Histone Deacetylase 2 in Epigenetics and Cellular Senescence: Implications in Lung Inflammaging and COPD," American Journal of Physiology_Lung Cellular and Molecular Physiology, Vol. 303, No. 7, 2012, pp. L557-L566. doi:10.1152/ajplung.00175.2012

[89] M. Stapleton, et al., "Smoking and Asthma," The Journal of the American Board of Family Medicine, Vol. 24, No. 3, 2011, pp. 313-322. doi:10.3122/jabfm.2011.03.100180

[90] D. Adenuga, et al., "Histone Deacetylase 2 Is Phosphorylated, Ubiquitinated, and Degraded by Cigarette Smoke," American Journal of Respiratory Cell and Molecular Biology, Vol. 40, No. 4, 2009, pp. 464-473. doi:10.1165/rcmb.2008-0255OC

[91] G. O. Osoata, et al., "Nitration of Distinct Tyrosine Residues Causes Inactivation of Histone Deacetylase 2," Biochemical and Biophysical Research Communications, Vol. 384, No. 3, 2009, pp. 366-371. doi:10.1016/j.bbrc.2009.04.128

[92] T. Toyooka and Y. Ibuki, "Cigarette Sidestream Smoke Induces Phosphorylated Histone H2AX," Mutation Research, Vol. 676, No. 1-2, 2009, pp. 34-40. doi:10.1016/j.mrgentox.2009.03.002

[93] B. S. Kim, et al., "Xanthine Oxidoreductase Is a Critical Mediator of Cigarette Smoke-Induced Endothelial Cell DNA Damage and Apoptosis," Free Radical Biology \& Medicine, Vol. 60, 2013, pp. 336-346. doi:10.1016/j.freeradbiomed.2013.01.023

[94] I. K. Sundar, et al., "Mitogen- and Stress-Activated Kinase 1 (MSK1) Regulates Cigarette Smoke-Induced Histone Modifications on NF-KappaB-Dependent Genes," PLoS ONE, Vol. 7, No. 2, 2012, Article ID: e31378. doi:10.1371/journal.pone.0031378

[95] S. Chung, et al., "NF-KappaB Inducing Kinase, NIK Mediates Cigarette Smoke/TNFalpha-Induced Histone Acetylation and Inflammation through Differential Activation of IKKs," PLoS ONE, Vol. 6, No. 8, 2011, Article ID: e23488. doi:10.1371/journal.pone.0023488

[96] M. Li, et al., "Effect of Erythromycin on CigaretteInduced Histone Deacetylase Protein Expression and $\mathrm{Nu}-$ clear Factor-KappaB Activity in Human Macrophages in Vitro," International Immunopharmacology, Vol. 12, No. 4, 2012, pp. 643-650. doi:10.1016/j.intimp.2011.12.022

[97] K. Takahashi, et al., "Cigarette Smoking Substantially Alters Plasma MicroRNA Profiles in Healthy Subjects," Toxicology and Applied Pharmacology, 2013. (in Press) doi:10.1016/j.taap.2013.05.018

[98] F. Schembri, et al., "MicroRNAs as Modulators of Smoking-Induced Gene Expression Changes in Human Airway Epithelium," Proceedings of the National Academy of Sciences of the United States of America, Vol. 106, No. 7, 2009, pp. 2319-2324. doi:10.1073/pnas.0806383106

[99] J. W. Graff, et al., "Cigarette Smoking Decreases Global MicroRNA Expression in Human Alveolar Macro-phages," PLoS ONE, Vol. 7, No. 8, 2012, Article ID: e44066. doi:10.1371/journal.pone.0044066

[100] S. Xi, et al., "Cigarette Smoke Induces C/EBP-BetaMediated Activation of miR-31 in Normal Human Res- 
piratory Epithelia and Lung Cancer Cells," PLOS ONE, Vol. 5, No. 10, 2010, Article ID: e13764.

doi:10.1371/journal.pone.0013764

[101] S. Xi, et al., "Cigarette Smoke Mediates Epigenetic Repression of miR-487b during Pulmonary Carcino-Genesis," The Journal of Clinical Investigation, Vol. 123, No. 3, 2013, pp. 1241-1261. doi:10.1172/JCI61271

[102] T. K. Ng, et al., "Nicotine Alters MicroRNA Expression and Hinders Human Adult Stem Cell Regenerative Potential," Stem Cells and Development, Vol. 22, No. 5, 2013, pp. 781-790. doi:10.1089/scd.2012.0434
[103] N. Rabinovitch, et al., "The Response of Children with Asthma to Ambient Particulate Is Modified by Tobacco Smoke Exposure," American Journal of Respiratory and Critical Care Medicine, Vol. 184, No. 12, 2011, pp. 1350-1357. doi:10.1164/rccm.201010-1706OC

[104] A. Kohli, et al., "Secondhand Smoke in Combination with Ambient Air Pollution Exposure Is Associated with Increasedx $\mathrm{CpG}$ Methylation and Decreased Expression of IFN-Gamma in T Effector Cells and Foxp3 in $\mathrm{T}$ Regulatory Cells in Children," Clinical Epigenetics, Vol. 4, No. 1, 2012, p. 17. doi:10.1186/1868-7083-4-17 